\title{
RELIABILITY PERFORMANCE OF WIRELESS SENSOR NETWORK FOR CIVIL INFRASTRUCTURE - PART I: EXPERIMENTAL ANALYSIS
}

\author{
Won-Suk JANG ${ }^{\mathrm{a}}$, Du Yon KIM ${ }^{\mathrm{b}}$, Mirosław J. SKIBNIEWSKI ${ }^{\mathrm{c}}$ \\ ${ }^{a}$ Department of Civil Engineering, Yeungnam University, 214-1 Dae-Dong Gyeongsan-Si, \\ 712-749 Gyeongbuk, South Korea \\ ${ }^{b}$ School of Construction Engineering, Kyungil University, Hayang, Gyeongsan-Si, \\ 712-701 Gyeongbuk, South Korea \\ ${ }^{c}$ Department of Civil and Environmental Engineering, University of Maryland, College Park, \\ 20742 MD, USA
}

Received 18 Jun 2013; accepted 19 Sep 2013

\begin{abstract}
Ubiquitous computing has changed the shape of the construction industry by providing a tool of automated sensing and monitoring the construction events using wireless sensor networks (WSNs). On the other hand, wireless signals are vulnerable to a range of environmental factors, such as obstructions from built structures, construction materials and equipment. Moreover, attenuation of the signal performance from the obstructions might reduce the reliability of the WSN performance for possible applications to civil infrastructure. This paper reports the experimental findings by simulating detailed obstruction environments using major construction materials to analyze the performance reliability of wireless communication. The T-R separation distance, construction materials, and their thickness have been identified as potential attenuation components, which were also analyzed quantitatively using the path loss exponent, attenuation index and cumulative beta distribution. The results from this research are expected help general civil engineers evaluate the performance of WSNs in the applications of civil infrastructure.
\end{abstract}

Keywords: WSN reliability, wireless sensor networks, signal performance, ZigBee, path loss.

\section{Introduction}

The new paradigm of ubiquitous computing is gradually changing the traditional interactions between users and computers in all industrial areas. As the size and complexity of construction projects increase, the concept of ubiquitous computing with the support of wireless sensor networks (WSNs) and mobile devices has attracted the attention of civil engineers for automation in construction management. Typical WSN applications in construction areas include the following: measurements of the physical quantity during the construction process, materials and equipment tracking and monitoring, real-time operation of construction processes, long-term structural health monitoring and safety monitoring. These applications require a real-time and reliable WSN framework to capture the in-situ events of a construction environment. At the same time, WSNs should provide a long-term monitoring system with high energy efficiency to survive a harsh environment, such as construction sites. Among the various wireless technologies, ZigBee is considered a potential solution for industrial monitoring and automation (Hwang et al. 2010). The applicability and robustness of ZigBee has attracted increasing attention not only in construction areas, but also in many industrial sectors, such as manufacturing and plants, because of its small size, low power, low cost, network scalability and selfconfiguring mechanism.

Fundamentally, a wireless signal is vulnerable to a range of environmental factors because electromagnetic propagation is often obstructed by physical objects and other types of signals (Sung, Yang 2010). Because construction sites have an atypical layout with built structures, construction materials and equipment, they are often recognized as unfavourable environments for the reliable communication of WSNs (Jo et al. 2013). The physical obstructions cause signal attenuation by multiple reflections, and the corresponding energy losses decrease the signal power and reliability at the receiver (Jadhavar, Sontakke 2012). If wireless sensors are placed and used without a proper evaluation of the communication performance, the entire wireless system might have trouble providing reliable measurements over existing wired systems. As the network size and number of sensors have increased, it is more important for the users to examine the quantitative reliability for designing an efficient network topology and for estimating the WSN operation

Corresponding author: Won-Suk Jang

E-mail:wsjang@ynu.ac.kr 
cost. Although there are a range of research efforts related to WSN applications in civil and construction areas, little research has been performed on a quantitative and experimental evaluation of the WSN performance.

This paper presents the experimental findings that can help analyse the performance reliability of wireless communications and design an efficient network topology for possible applications in civil infrastructure. In this research, field experiments have been conducted to evaluate the signal attenuation obstructed by major construction materials using a $2.4 \mathrm{GHz}$ ZigBee wireless module. In addition, analytical methodologies were also addressed to quantify the performance of WSNs in applications to civil infrastructure.

\section{Literature review}

An interest on wireless communication technologies at construction sectors is increasing, resulting in active research and development activities on applications. It has been reported that ZigBee among several wireless communication technologies such as Bluetooth and WiFi shows excellent performances under various hindering environments like industrial sites based on its advantages including low power consumption of $2.4 \mathrm{GHz}$ band, low cost and convenient network scalability (Panitz et al. 2008). One of the most representative areas applied with ZigBee among construction industry sectors is the bridge monitoring sector, and Xiao et al. (2011) proposed a methodology to evaluate the structural health and damage of bridges by measuring the vibration data of bridge structures with the vehicles traveling at any time. Chae et al. (2012) developed a bridge monitoring system that is capable of collecting long-distance data measured through 5 types of 45 sensors installed at a suspension bridge by using ZigBee and Code Division Multiple Access (CDMA). Moreover, Liu and Teng (2010) presented a system that enables measuring of bridge movement in real time using an acceleration sensor applied with ZigBee and providing immediate information via $3 \mathrm{G}$ network to controllers when a danger is detected. Bocca et al. (2011) used a wireless sensor network that can measure temperature, humidity and acceleration to carry out an experiment with a wooden bridge model.

In other application studies, it has been reported that the ZigBee functions of wireless data transmission/reception and position tracking are used for resource management systems of construction materials, workers and equipment as well as for work process management, safety management of workers at construction sites and productivity measurement. Kim et al. (2011) selected RFID and $\mathrm{ZigBee}$ as the wireless communications methods to track physical distribution of construction materials in real time. Zhang and Wei (2012) regarded construction workers as mobile nodes to measure RSSI from the ZigBee module carried by such workers and proposed hardware and software designs that can perform positioning and tracking. Raj and Varghese (2012) suggested a position (location) tracking system that can promote improvement of construction productivity and secure safety of workers. Naticchia et al. (2013) proposed a methodology for inspectors to monitor construction workers in real time with efficiency. In the literature on safety management areas, ZigBee-based self-locking strategy and variant binary exponential back-off (BEB) messaging model was suggested for stable operation of the construction hoist on site (Yang et al. 2012). In addition, a building electrical safety monitoring system to improve electrical safety of buildings and increase efficiency of power supply units was proposed (Huang et al. 2011). Slope monitoring system (Chang et al. 2013; Kim, Han 2008), irrigation control monitoring system (Rasin et al. 2009), tunnel monitoring system (Kim et al. 2008), safety monitoring at mines (Boddu et al. 2012), livestock monitoring system (Nadimi et al. 2008), and u-healthcare services (Lee et al. 2009) are the examples of ZigBee-based applications.

There have been numerous application studies focused on the advantages of ZigBee, yet there are several literatures indicating the communication reliability issue caused by physical limitation of wireless communication. Unlike the wired communication network technologies, ZigBee-based wireless network shows low data rate and high bit error ratio. Since additional tasks of packet transmission and protocol execution are required, network efficiency and reliability may decrease according to the data transmission algorithm (Sung et al. 2010). In addition, when a network is composed of multiple wireless nodes resulting in poor network connectivity owing to various errors, system efficiency will be declined and deployment cost increased (Sung, Yang 2010). These failures or errors of wireless communications occur at construction cases (Xiao et al. 2011; Chae et al. 2012; Kim et al. 2011; Raj, Varghese 2012; Yang et al. 2012), and it has been pointed out that depending on the reception environment such as the existence of construction obstacles, the received signal strength may be reduced, data packet may be lost and the reception rate declined.

\section{Experimental configuration}

\subsection{Hardware setup}

This study examined the quantitative level of wireless signal attenuation in a construction environment. By varying the type and dimensions of construction materials, a field experiment with a $2.4 \mathrm{GHz}$ ZigBee module was performed in both line-of-sight (LOS) and non-line of sight (NLOS) environment. For the NLOS environment, the object samples with typical construction materials, e.g. plywood $(500 \times 500 \times 20 \mathrm{~mm})$, concrete block $(300 \times 300 \times 120 \mathrm{~mm}$ without reinforcement $)$ and steel plate $(300 \times 300 \times 10 \mathrm{~mm})$, are designed. The receiving node connected to a laptop was placed at a fixed point to measure the receiving signal power, and a transmitting node was moved away from the receiving node in 1 meter increments until the receiving node could not 

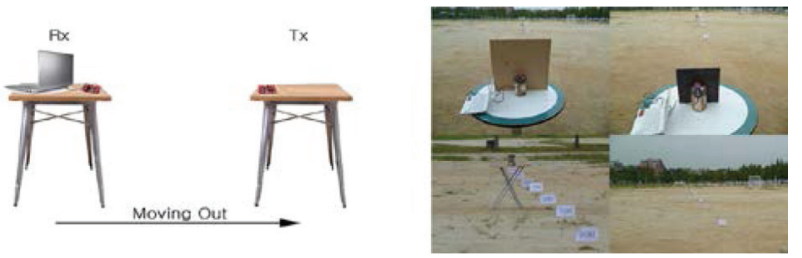

Fig. 1. Experimental setup

detect any incoming signals (Fig. 1). By varying the thickness and type of construction materials, the transmitting node periodically sends data packets with a 6 byte payload per second until 1,000 data samples are measured at each unit distance. The performance criteria, such as received signal strength index (RSSI), link quality index (LQI) and packet delivery rate (PDR), were measured to evaluate quantitatively the wireless signal attenuation in the obstructed environment. In this experiment, ZigBee equipped with a CC2420 radio transmitter set to a maximum power level, $0 \mathrm{dBm}$, was used.

\subsection{Software setup}

TinyOS is a component-based operating system developed from the Smart Dust project in the University of California at Berkeley, Intel Research and Crossbow Technology targeting wireless sensor networks (WSNs). TinyOS provides a free and open source platform for efficient sharing and updates by communities of embedded systems and WSNs. The operating system was optimized for WSN hardware resources: a small compilation size, limited memory, low CPU, low power and small size. TinyOS resolves the specific challenges of sensor networks for limited hardware resources and application-specific requirements by a range of implementations of both operating system services and applications.

Based on the TinyOS specifications, the software model at the transmitter, receiver, and post processes was developed for field experiments. First, a sending model was compiled and constructed on a transmitter node for transmitting a data packet that includes node ID, Tx_Power, and counter at $1 \mathrm{~Hz}$ intervals. As is described in Figure 2, a $1 \mathrm{~Hz}$ timer was fired to generate periodically the structure of a data packet, where 2 bytes node ID and 4 bytes counter variables were allocated. Whenever a data packet was generated, a counter value that increased by one each time was stored on the payload in the data packet and sent to a receiving node together with the transmission power level and node ID. The counter value indicates the total number of transmissions and is used to calculate the packet delivery rate at the receiver side.

Second, a receiving model was designed to receive the data packets from the transmitter. Whenever the Receive event was activated, the GetPayload interface was called to put the receiving variable to a structure buffer, and the size of structure and pointer address were examined. When the success of packet reception was confirmed, the event handler was operated to measure the RSSI and LQI, which were defined in the
IEEE 802.15.4 specifications, and generated another counter that increases the number of packet receptions. The parent's node ID, receiver's node ID, transmission counter, reception counter, RSSI, LQI, and transmission power were then stored and carried out through UART (Universal Asynchronous Receiver/Transmitter) to a PC.

Finally, post processing model was developed using Java to analyse the PDR and provide a user-friendly interface. When a hex stream of a data packet is received through UART at a PC, the data format was changed to decimal format. All the received data, including the time stamp, was then written in a user-defined text file for further processes or GUI (Graphical User Interface). Figure 3 illustrates the a sample Java application developed to plot real-time RSSI data collected to Base Station through serial port.

\section{Analysis of wireless signal attenuation in obstructed environment}

To analyse the attenuation effect, a field experiment was conducted with programmed sensor nodes to measure the performance criteria, e.g. RSSI, LQI, and PDR, in a lineof-sight environment (extended from Bae et al. 2013). Figure 4 describes the performance criteria along with the increasing T-R separation distance. As shown in the figure, RSSI showed strong power loss by decreasing drastically at a near-field separation distance of up to 20 meters. Beyond that, it decreased slowly and converged to $-90 \mathrm{dBm}$ at a T-R separation of up to 80 meters. LQI also decreased with increasing separation distance but in a smooth curve pattern, and 40\% LQI was measured at an $80 \mathrm{~m}$ separation distance. Similarly, PDR decreased with increasing separation distance, but the decreasing rate was much higher in the far-field than in the near-field.

On the other hand, signal attenuation showed a different pattern in the obstructed environment where plywood, concrete block, or steel plate was placed immediately behind a receiver blocking the direct line-ofsight path of the transmitting signal. Similar to concrete material, the dielectric constant ranges from 2 to 2.5 , and the signal reflected from plywood panel reduces a certain amount of the signal strength at the receiver side due to energy absorption. Figure 5 shows the spectrum of RSSI, LQI and PDR according to the T-R separation distance when the signal is blocked by a 4 to $20 \mathrm{~cm}$ thick sheet of plywood. Basically, the received signal is a function of the T-R separation distance, which is similar to the case of LOS, but the level of attenuation increases with increasing plywood thickness. At the closest T-R separation, the measured RSSI of $4 \mathrm{~cm}$ thick plywood was $-52 \mathrm{dBm}$, e.g. more signal loss by $12 \mathrm{dBm}$ than the case of LOS. In $20 \mathrm{~cm}$ thick plywood, the measured RSSI at the closes distance decreased to $-62 \mathrm{dBm}$ and the signal could be detected up to a $53 \mathrm{~m}$ T-R separation. LQI and PDR showed similar pattern to the case of LOS, but the curves began decreasing faster and RF coverage decreased more than the case of LOS. 


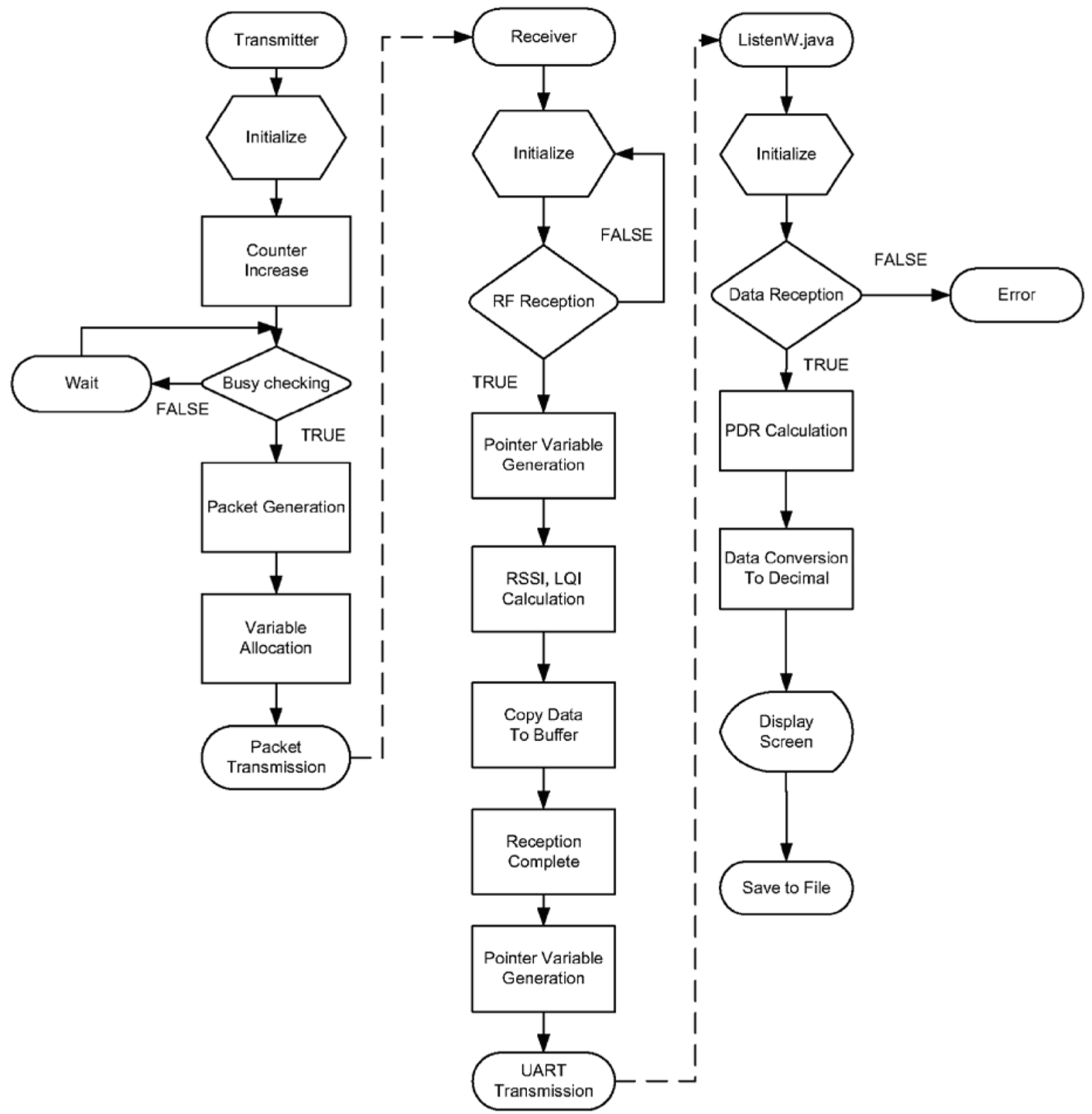

Fig. 2. Flowchart of a ZigBee programming

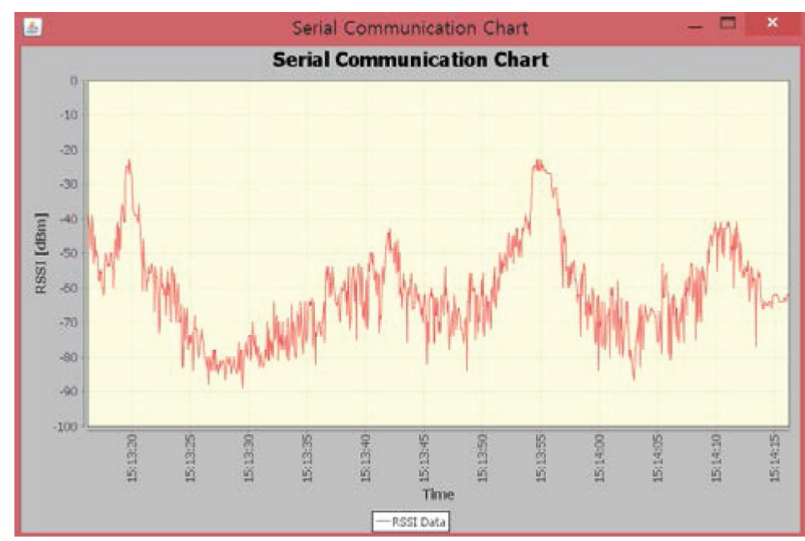

Fig. 3. A screenshot of Java application for plotting real-time RSSI measurement through serial port at a base station node
Concrete block is a lossy dielectric material that absorbs a certain amount of radio energy, reducing the signal strength at the receiver side. When combined with reinforcement, the concrete block shows unpredictable attenuation in signal propagation. In particular, the thickness of the concrete block becomes larger than other construction materials when used as a structural component. Therefore, the wireless signals penetrating through the thick concrete show serious attenuation in strength. This phenomenon is clearly observed in the test results shown in Figure 6, where the spectrum of RSSI, LQI and PDR were measured by varying the thickness of the concrete block from 12 to $60 \mathrm{~cm}$. The wireless signals penetrating a $12 \mathrm{~cm}$ and $60 \mathrm{~cm}$ thick concrete block could travel up to 


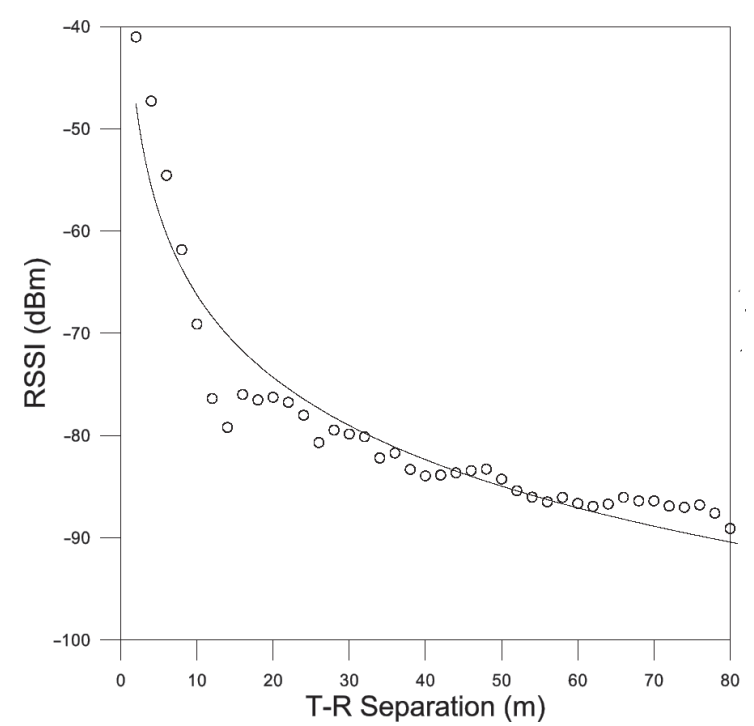

(a) RSSI

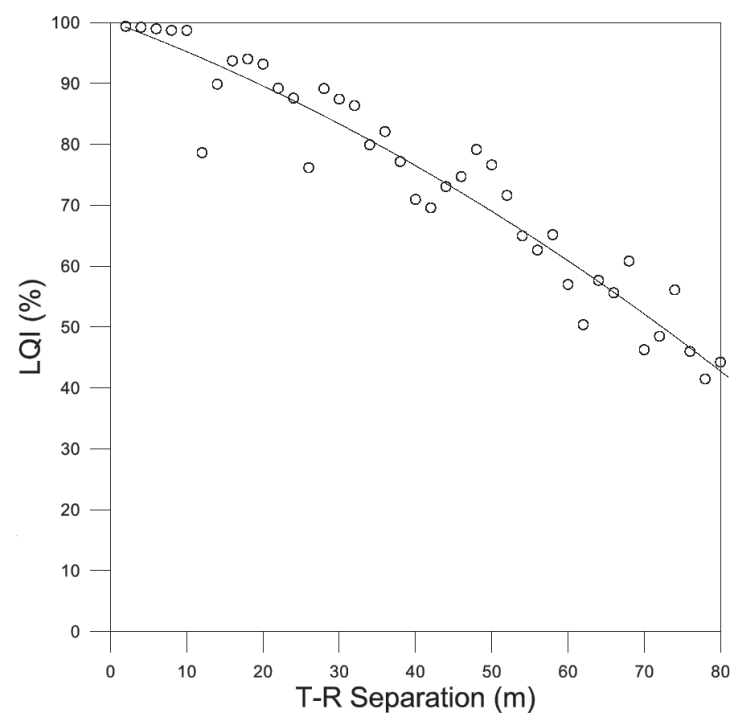

(b) LQI

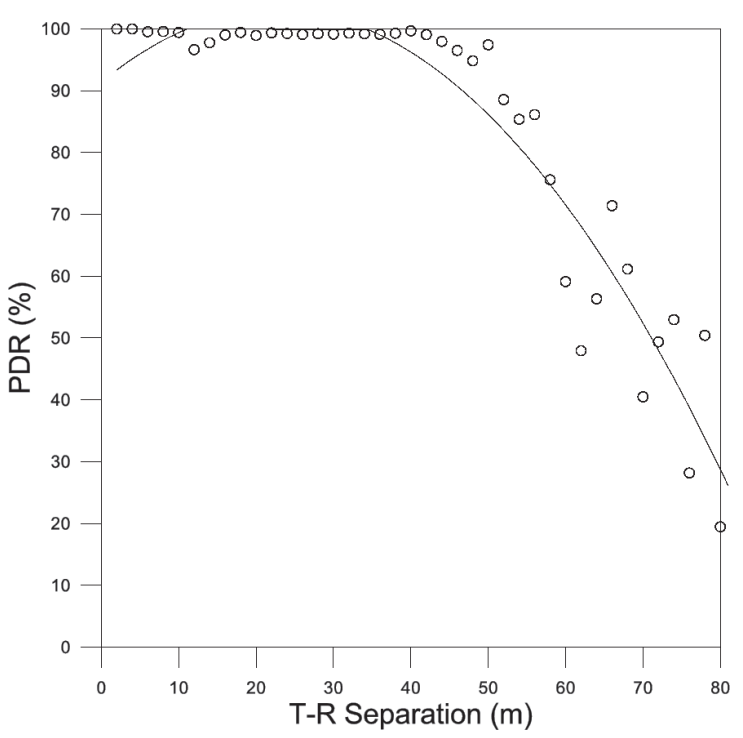

(c) PDR

Fig. 4. Performance measurements in a line-of-sight environment

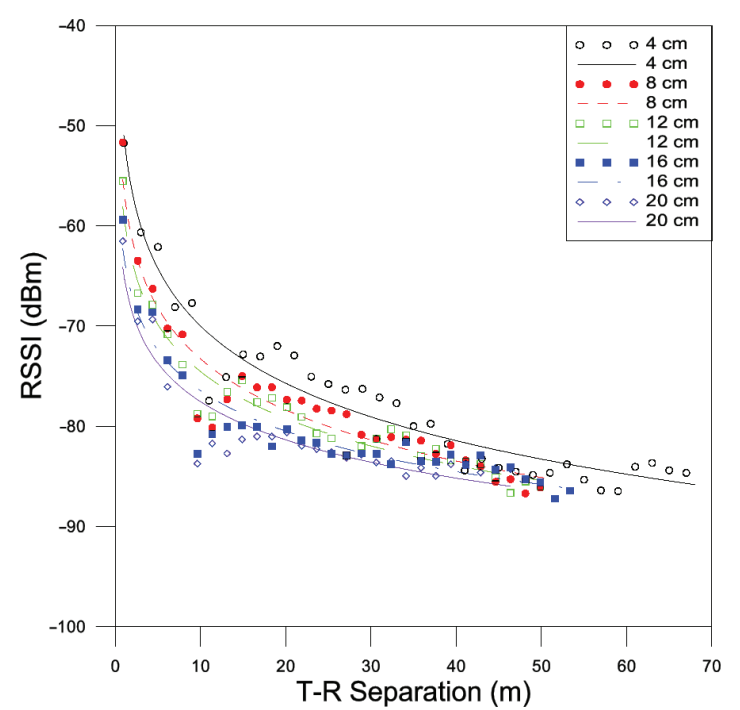

(a) RSSI

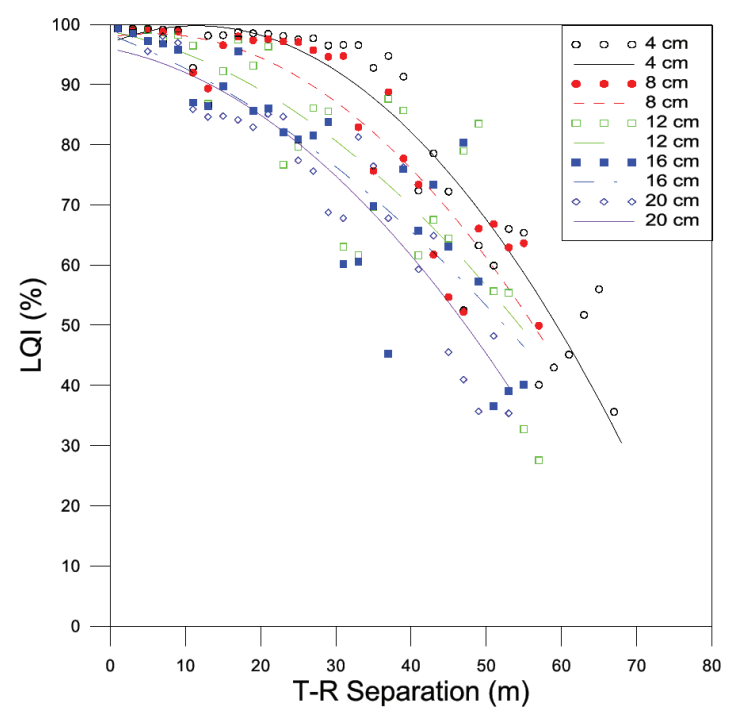

(b) LQI

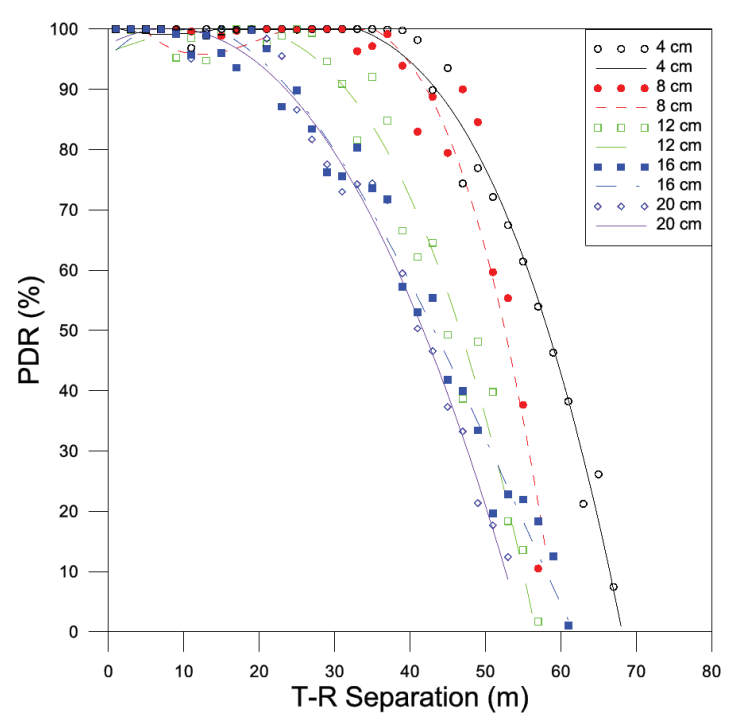

(c) PDR

Fig. 5. Performance measurements in an obstructed environment (Plywood) 
71 and 60 meters, respectively. The RSSIs with $12 \mathrm{~cm}$ and $60 \mathrm{~cm}$ thick concrete blocks showed $-45 \mathrm{dBm}$ and $-65 \mathrm{dBm}$ at the closest distance, respectively, which then decreased in a $\log$ fashion up to approximately $-90 \mathrm{dBm}$. The LQI and PDR also decreased much more than those in LOS and the level of attenuation increased with increasing thickness of the concrete block.

Unlike dielectric materials, such as plywood and concrete, steel is a strong electromagnetic conductor, and vast amounts of energy are reflected when blocked by obstructions, resulting in a serious decrease in the penetrating wave and signal strength received. To analyse the quantitative amount of signal attenuation, the test configuration was set in a way that a single hop wireless communication was blocked by a steel plate ranging in thickness from 1 to $10 \mathrm{~cm}$. Figure 7 shows each measurement criterion, indicating a serious decrease in the T-R separation distance, ranging from 50 to $10 \mathrm{~m}$ in a 1 and $10 \mathrm{~cm}$ thick steel plate, respectively. The LQI and PDR also showed sharp and almost linear decreases with increasing T-R separation distance. A comparison of the test results measured from a similar thickness of objects showed that the measurement criteria in the case of plywood and concrete do not differ significantly. This might be because the dielectric constant of two different materials is similar, ranging from 2.1 to 2.5. Therefore, the attenuation effect of a penetrating signal through the object would be similar. On the other hand, the test results of a steel plate showed serious drops in RSSI, LQI and PDR due to the material characteristics as a conductor that would reflect most of the RF energy.

\section{Quantitative comparison of wireless signal attenuation}

The path loss exponent, $n$, indicates the rate at which the path loss increases with increasing T-R separation, depending on the specific radio propagation environment, such as urban areas, obstructions in buildings, or obstructions in factories. In particular, Seidel and Rappaport (1992) categorized the parameters of the path loss exponent according to type of office buildings with different floor levels. On the other hand, previous studies did not fully address the obstruction details, such as the type of construction materials or their thickness. Therefore, it is difficult to predict the pure contribution to the signal attenuation, which is a major cause of the attenuation confusion.

Figure 8 shows the path loss exponent from the measured signal strength according to the change in material and thickness by considering detailed obstruction characteristics. The mean path loss of a different obstruction thickness was measured at a fixed point and plotted alongside the T-R separation distance. The straight lines indicate the distance-dependent path loss with the path loss exponent, $n$, representing the

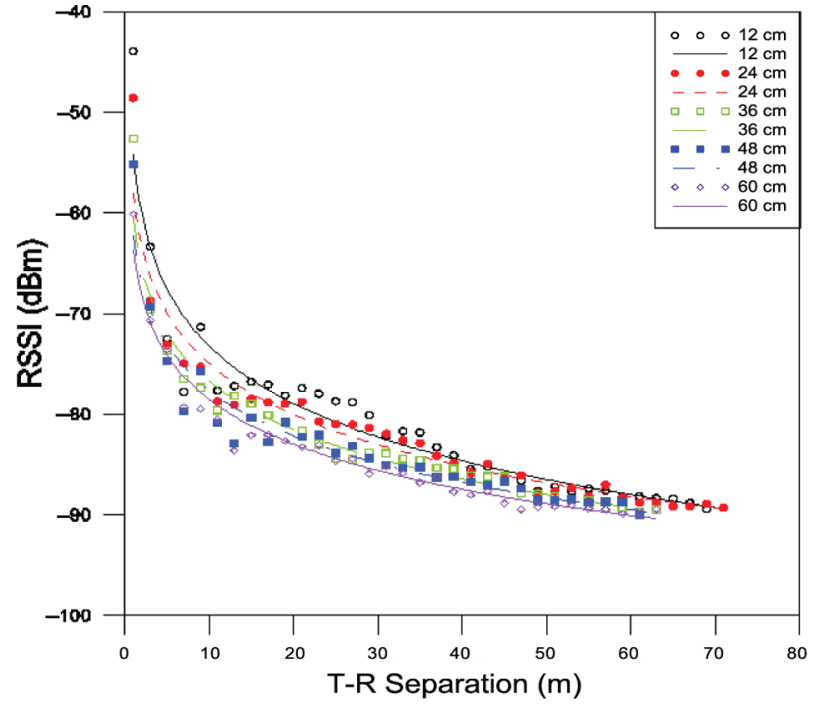

(a) RSSI

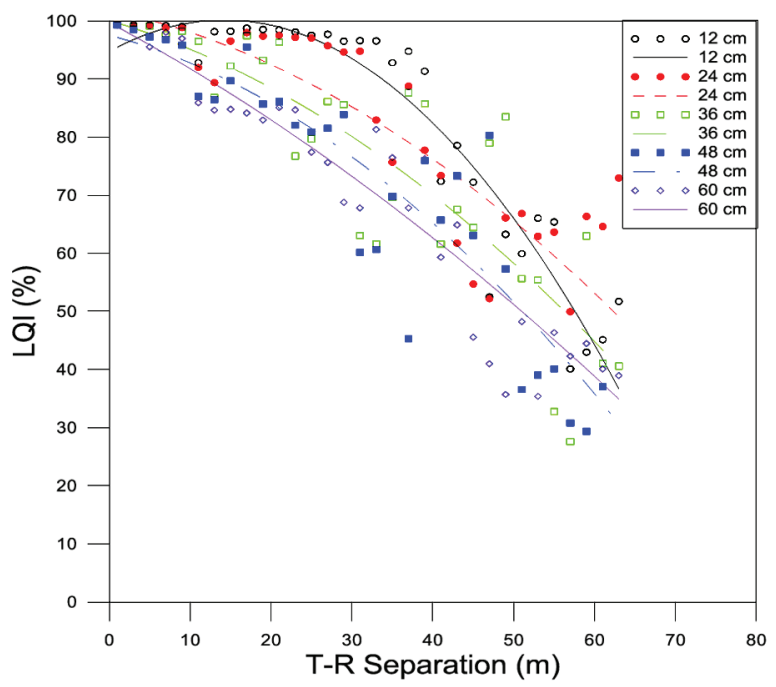

(b) LQI

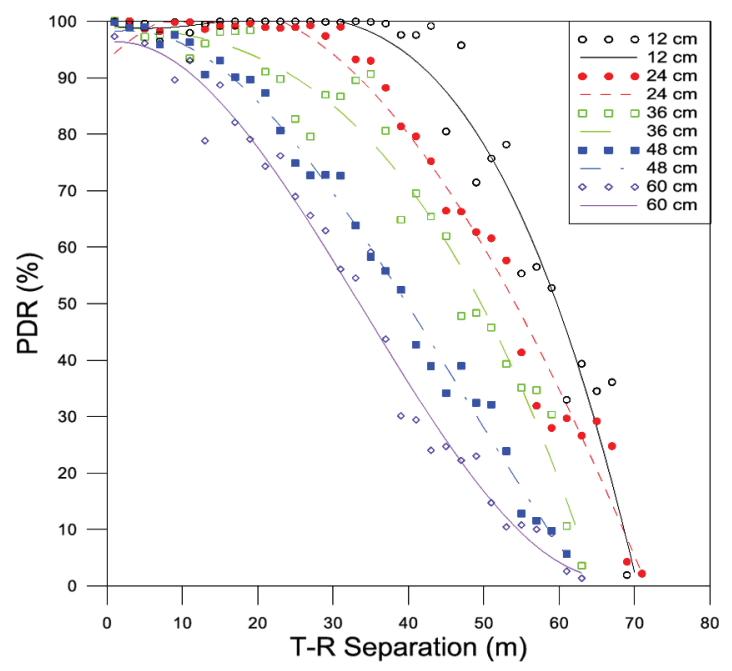

(c) PDR

Fig. 6. Performance measurements in an obstructed environment (Concrete block) 


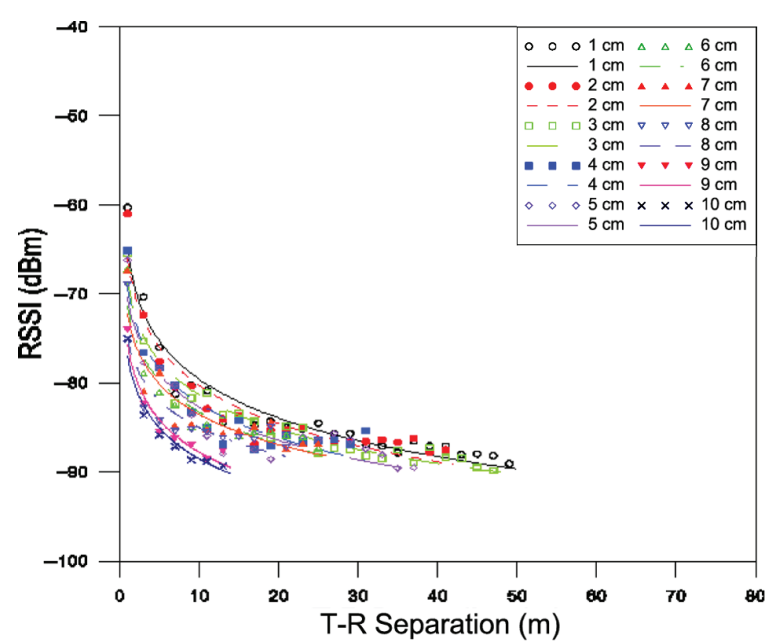

(a) RSSI

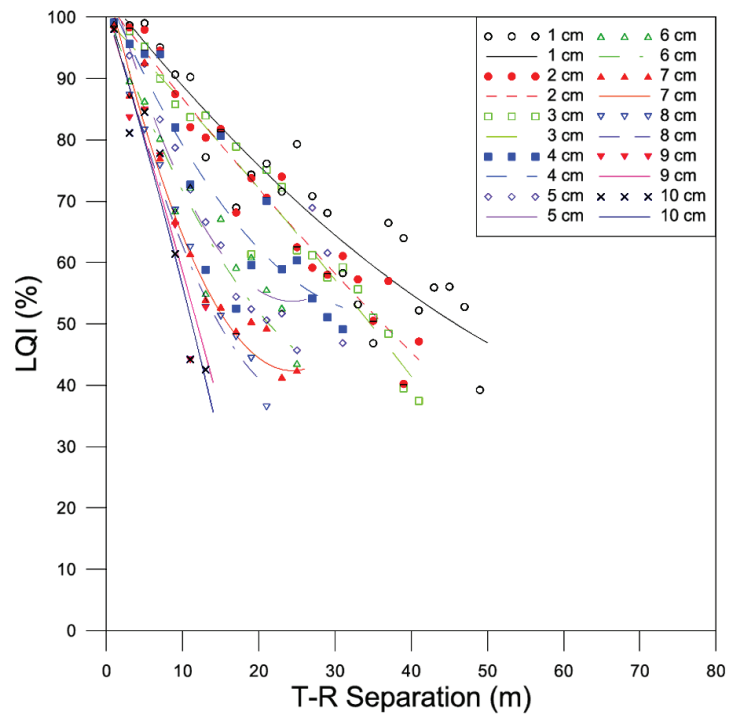

(b) LQI

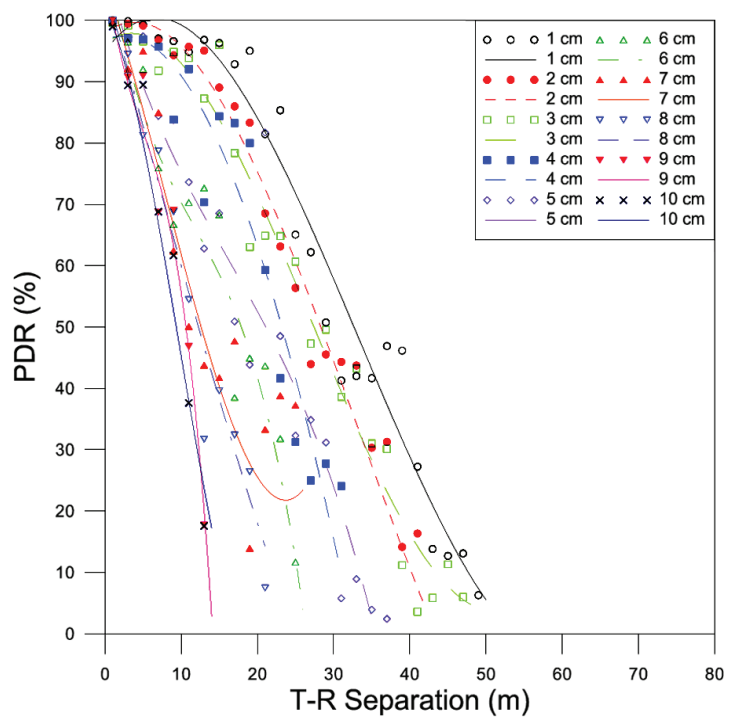

(c) PDR

Fig. 7. Performance measurements in an obstructed environment (Steel plate)

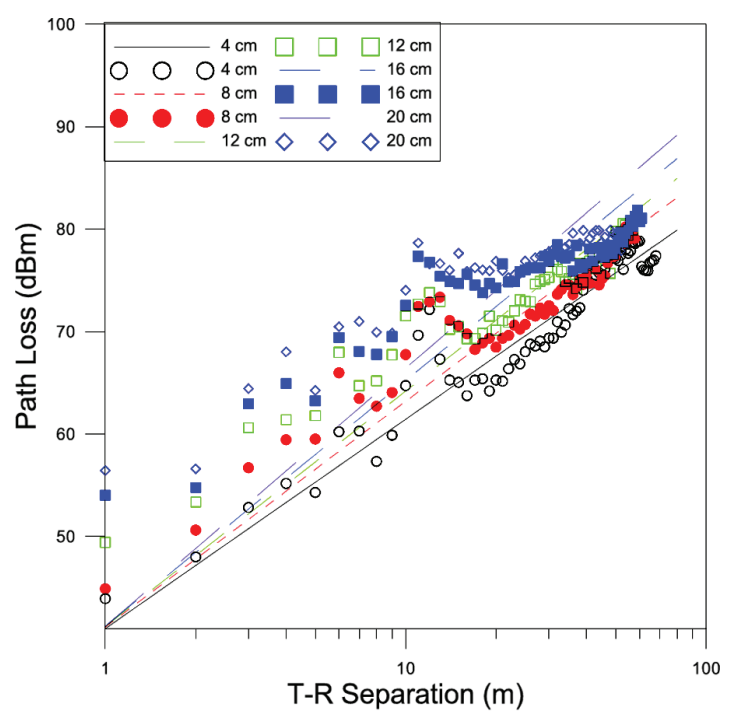

(a) Plywood

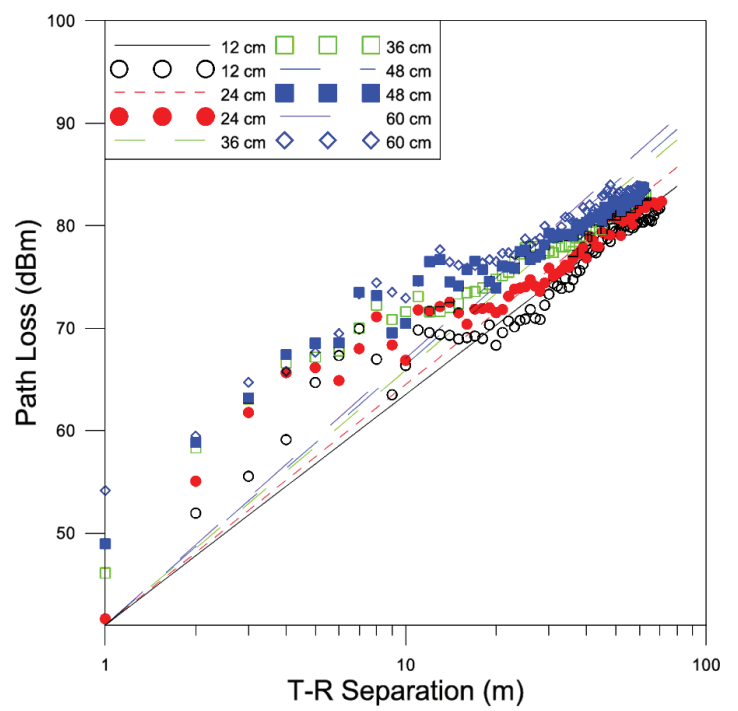

(b) Concrete block

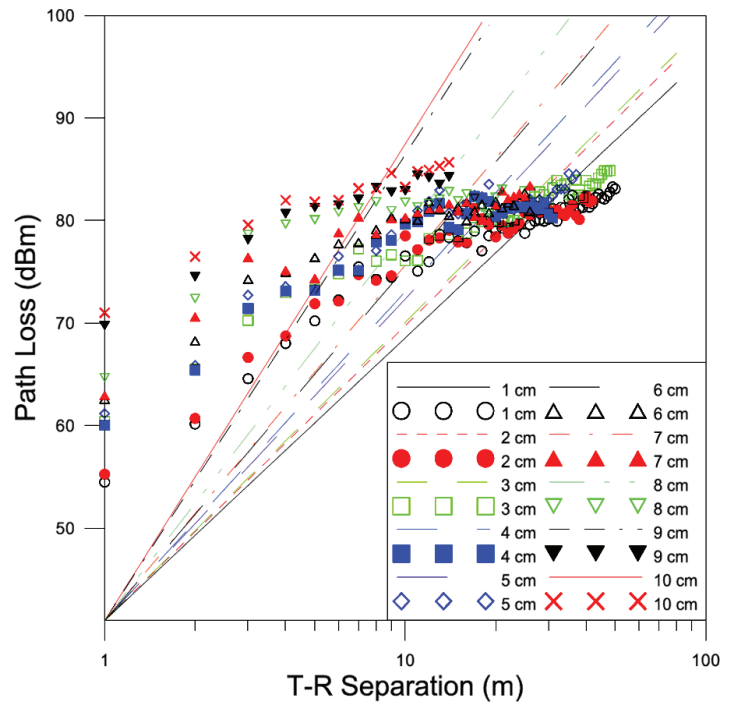

(c) Steel plate

Fig. 8. Path loss measured from obstructed environment 
increasing rate of path loss in a different propagation environment (Table 1). When the path loss exponents are compared with the material type, plywood and concrete block were slightly larger than the environment categorized as free space, but the steel plate showed the largest path loss exponent, even with a relatively thin obstruction thickness. This means that the path loss from a reference distance along with the T-R separation distance is more severe in a steel plate than the other types of material.

The path loss is basically measured by the distribution of RSSI and might not represent the typical performance of signal attenuation. In this study, the attenuation index (AI), as another possible indicator from a cumulative differential dataset, was proposed to analyse the reliability of wireless signal quantitatively. The cumulative differential dataset was defined by the normalized measurement of accumulated deviation calculated in each interval of the T-R separation distance. In addition, the attenuation index (AI) could be defined as the value of the linear regression slope obtained from the cumulative differential dataset. When the level of signal obstruction is large, the deviation of the measurements between adjacent T-R separation points increased, resulting in an increased number of attenuation indices. In this way, it is possible to include both the LQI and PDR, and to compare the level of signal attenuation quantitatively according to the characteristics of the obstruction type and thickness.
If $y_{i}$ is defined as the cumulative differential dataset at the $i^{\text {th }} \mathrm{T}-\mathrm{R}$ separation, numerical formulation to calculate $y_{i}$ can be expressed as:

$$
y_{i+1}=y_{i}+\left|\frac{\left(x_{i+1}-x_{i}\right)}{\left(d_{i+1}-d_{i}\right)}\right|,(i=1,2, \ldots, N),
$$

where $x_{i}$ is the performance criteria, e.g. RSSI, LQI or PDR, at the $i^{\text {th }}$ T-R separation distance; $d_{i}$ is the T-R separation at the $i^{\text {th }}$ location point; and $N$ is the total number of measurement points. The attenuation index, AI, can be calculated from the cumulative differential dataset using the slope of the linear regression function.

Figures 9 and 10 illustrate the normalized cumulative differential dataset of LQI and PDR and their linear regression curves in an obstructed environment. The slope of the linear regression curve, AI, increases with increasing thickness of the construction material. In particular, the AI of a steel plate is generally larger than other dielectric materials in both LQI and PDR. This suggests that a wireless signal penetrating through a steel plate reduced the received signal strength and signal reception rate more than through the other dielectric materials, indicating a higher deviation of measurements at each T-R separation distance. Table 2 lists the slope of the linear regression curve, i.e. AIs in each test case. Interestingly, AIs calculated from a steel plate were almost three times higher in RSSI and PDR

Table 1. Path loss exponent and standard deviation according to the materials and thickness

\begin{tabular}{|c|c|c|c|c|}
\hline Material Type & $\begin{array}{c}\text { Thickness } \\
{[\mathrm{cm}]}\end{array}$ & Number of location & $\begin{array}{c}\text { Standard } \\
\text { deviation }[\mathrm{dBm}]\end{array}$ & $\begin{array}{c}\text { Path Loss } \\
\text { exponent, } n\end{array}$ \\
\hline \multirow{5}{*}{ Plywood } & 4 & 67 & 7.81 & 2.04 \\
\hline & 8 & 57 & 6.91 & 2.20 \\
\hline & 12 & 56 & 6.31 & 2.30 \\
\hline & 16 & 60 & 5.59 & 2.40 \\
\hline & 20 & 52 & 5.29 & 2.52 \\
\hline \multirow{5}{*}{ Concrete block } & 12 & 69 & 7.82 & 2.25 \\
\hline & 24 & 70 & 6.94 & 2.35 \\
\hline & 36 & 62 & 6.50 & 2.49 \\
\hline & 48 & 61 & 6.20 & 2.54 \\
\hline & 60 & 62 & 5.94 & 2.60 \\
\hline \multirow{10}{*}{ Steel plate } & 1 & 49 & 5.77 & 2.76 \\
\hline & 2 & 41 & 5.71 & 2.87 \\
\hline & 3 & 47 & 5.00 & 2.91 \\
\hline & 4 & 30 & 5.13 & 3.21 \\
\hline & 5 & 36 & 4.99 & 3.14 \\
\hline & 6 & 25 & 4.60 & 3.44 \\
\hline & 7 & 25 & 4.45 & 3.46 \\
\hline & 8 & 20 & 4.19 & 3.80 \\
\hline & 9 & 13 & 4.19 & 4.54 \\
\hline & 10 & 13 & 4.01 & 4.65 \\
\hline
\end{tabular}




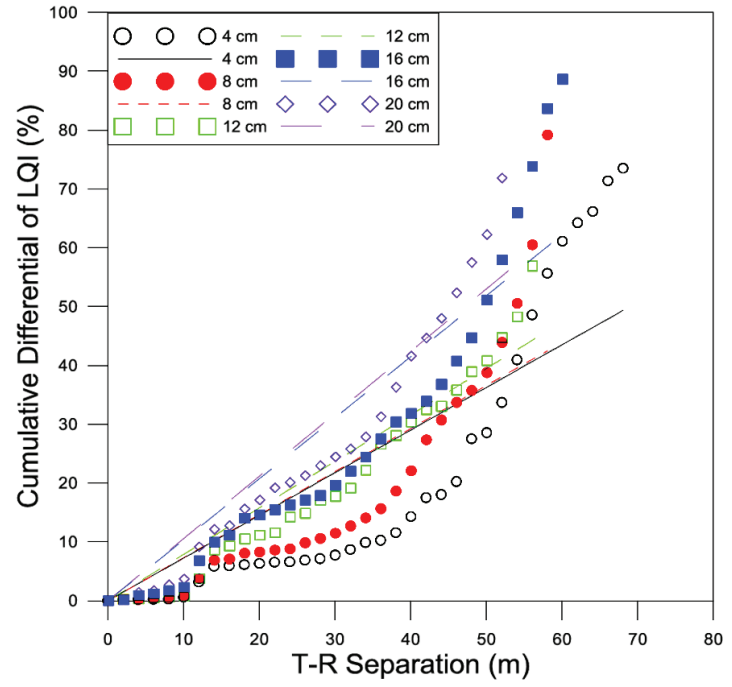

(a) Plywood

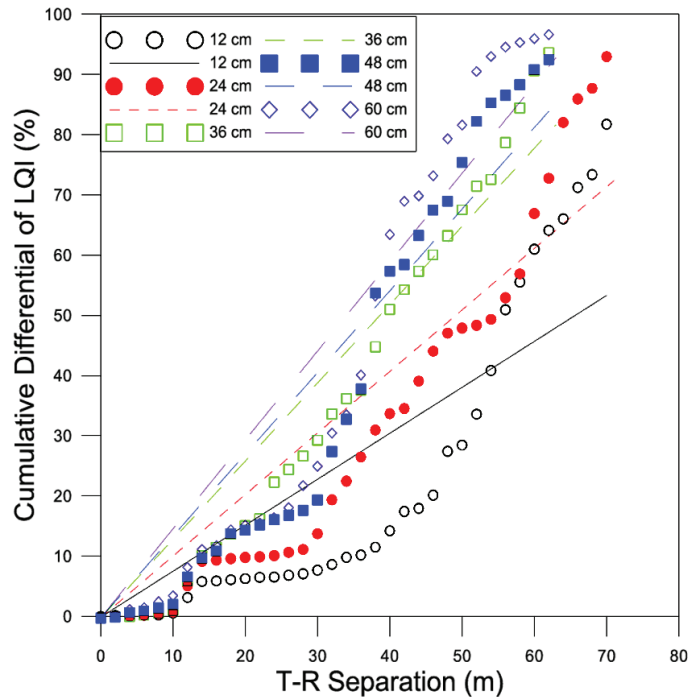

(b) Concrete block

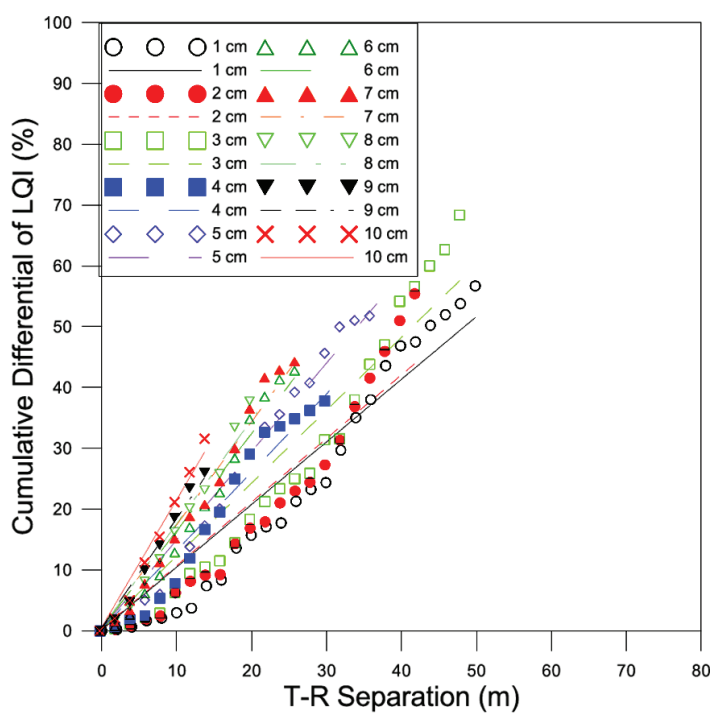

(c) Steel plate

Fig. 9. Cumulative differential dataset and regression curve of LQI in an obstructed environment

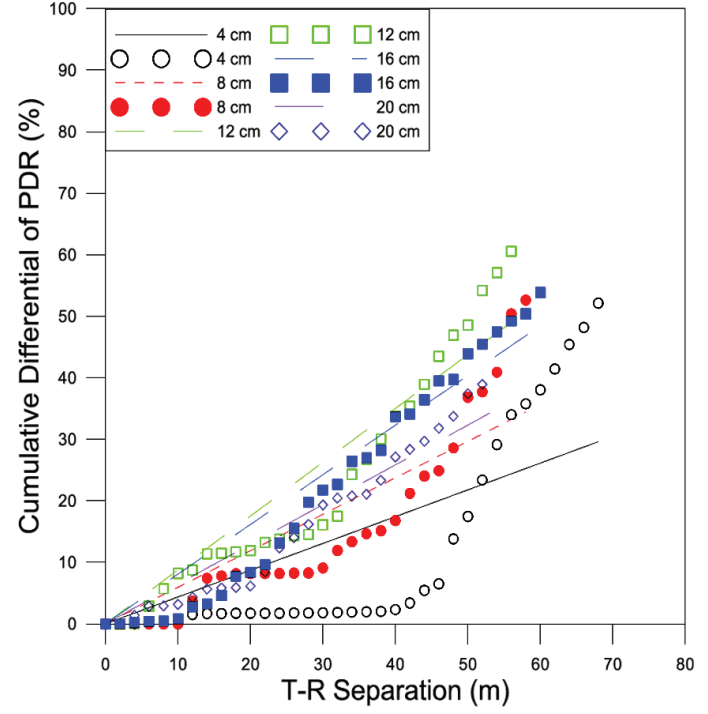

(a) Plywood

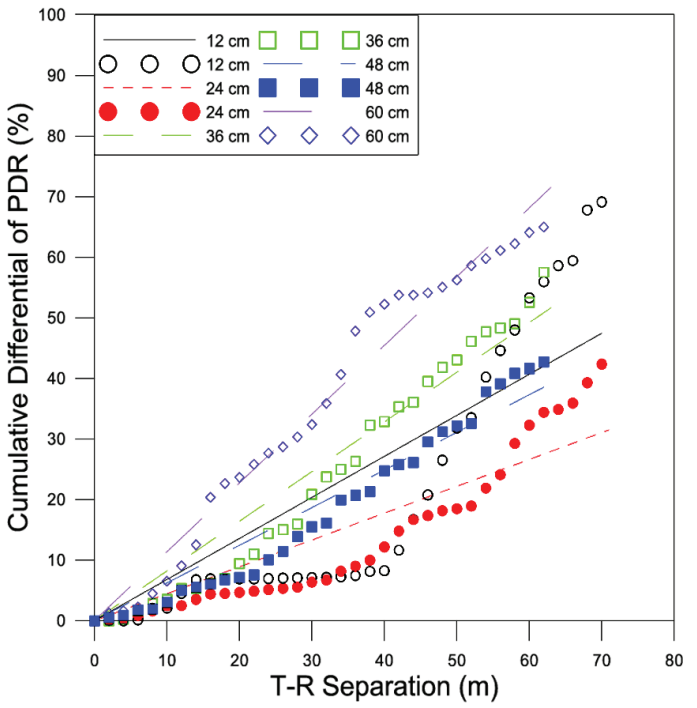

(b) Concrete block

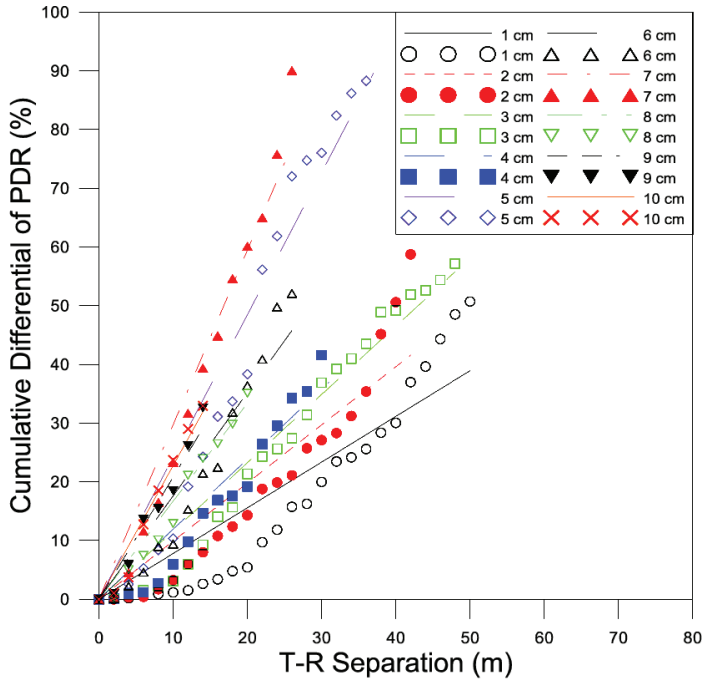

(c) Steel Plate

Fig. 10. Cumulative differential dataset and regression curve of PDR in an obstructed environment 
than other dielectric materials when similar thicknesses of the materials are compared. On the other hand, the AIs calculated by LQI from a similar thickness of the three different materials are less distinguished. By this phenomenon, it could be inferred that the performance criterion of RSSI or PDR is more sensitive to external disturbances than that of LQI. Although RSSI, LQI, and PDR are good indicators for evaluating an incoming signal, LQI is more like an indicator that measures the error in the incoming modulation of successfully received packets (Halder et al. 2011). Therefore, RSSI and PDR would be a better fit to assess the attenuation effect in a situation where the signal is disturbed from noises and interference.

If the performance measurement is assumed to be a continuous random variable within its coverage, the probability distribution becomes skewed such that the probability that a measurement of RSSI occurs is higher at the lower bound while the probability that LQI or PDR occurs is higher at the upper bound. By configuring the shape parameter, i.e. $\alpha$ and $\beta$, the distribution of the performance criteria can be expressed as the beta distribution. Table 3 lists the shape parameter beta with a fixed alpha of 2 according to the material type and thickness. The beta in each performance measurement generally increases with increasing thickness of each material type. Therefore, it has a good rational for inferring the interference effect from a comparison of the shape parameter beta. On the other hand, the increase in beta does not always coincide well with the increase in thickness. Rather, beta gives the implication of how much the probability distribution of each measurement is biased due to the material type. If beta $>2$, the probability density function becomes biased to a lower bound from a uniform distribution, whereas it is biased to an upper bound at beta $<2$.

The direction and level of bias can be well demonstrated in a cumulative distribution function (CDF), shown in Figure 11. In the case of RSSI, the average beta value was 4.31, 5.50 and 5.15 in plywood, concrete block and steel plate, respectively. The CDF appears above the straight line because beta $>2$, which shows that the performance measurement of RSSI is skewed to a lower bound. The more biased from a uniform distribution, e.g. moving to the left direction, such as a steel plate and concrete block, the higher the probability that the RSSI would be observed around the lower bound, indicating more interference from the obstructions.

On the other hand, the mean beta value is $1.46,1.63$, and 2.15 for LQI and $1.31,1.52$, and 1.75 for PDR in plywood, concrete block and steel plate, respectively. Because most beta values are less than 2, the CDF appears below the straight line, indicating that the measurements are skewed to the upper bound. In both cases of LQI and PDR, the less biased from a uniform distribution,

Table 2. Attenuation Index (AI) for different materials and thicknesses

\begin{tabular}{|c|c|c|c|c|c|c|c|c|c|}
\hline & & RSSI & LQI & PDR & & & RSSI & LQI & PDR \\
\hline LOS & & 1.42 & 0.63 & 0.66 & \multirow{7}{*}{ Steel plate } & $1 \mathrm{~cm}$ & 1.66 & 1.02 & 0.77 \\
\hline \multirow{3}{*}{ Plywood } & $4 \mathrm{~cm}$ & 1.52 & 0.72 & 0.43 & & $2 \mathrm{~cm}$ & 1.89 & 1.04 & 0.99 \\
\hline & $12 \mathrm{~cm}$ & 1.78 & 0.79 & 0.87 & & $4 \mathrm{~cm}$ & 2.49 & 1.28 & 1.19 \\
\hline & $20 \mathrm{~cm}$ & 2.01 & 1.06 & 0.64 & & $6 \mathrm{~cm}$ & 2.88 & 1.59 & 1.76 \\
\hline \multirow{3}{*}{$\begin{array}{l}\text { Concrete } \\
\text { block }\end{array}$} & $12 \mathrm{~cm}$ & 1.50 & 0.76 & 0.67 & & $8 \mathrm{~cm}$ & 3.49 & 1.71 & 1.66 \\
\hline & $36 \mathrm{~cm}$ & 1.64 & 1.30 & 0.82 & & $10 \mathrm{~cm}$ & 4.63 & 2.09 & \multirow[t]{2}{*}{2.22} \\
\hline & $60 \mathrm{~cm}$ & 1.72 & 1.47 & 1.13 & & & & & \\
\hline
\end{tabular}

Table 3. Shape parameter of the beta in the beta probability distribution according to materials and thickness $($ alpha $=2.0)$

\begin{tabular}{|c|c|c|c|c|c|c|c|c|c|}
\hline & & RSSI & LQI & PDR & & & RSSI & LQI & PDR \\
\hline LOS & & 4.42 & 1.60 & 1.26 & \multirow{11}{*}{ Steel plate } & $1 \mathrm{~cm}$ & 5.46 & 1.90 & 1.58 \\
\hline \multirow{5}{*}{ Plywood } & $4 \mathrm{~cm}$ & 4.04 & 1.39 & 1.22 & & $2 \mathrm{~cm}$ & 5.68 & 1.84 & 1.56 \\
\hline & $8 \mathrm{~cm}$ & 3.61 & 1.35 & 1.16 & & $3 \mathrm{~cm}$ & 4.87 & 1.95 & 1.83 \\
\hline & $12 \mathrm{~cm}$ & 4.07 & 1.41 & 1.30 & & $4 \mathrm{~cm}$ & 5.65 & 2.27 & 1.54 \\
\hline & $16 \mathrm{~cm}$ & 4.24 & 1.64 & 1.48 & & $5 \mathrm{~cm}$ & 4.89 & 2.24 & 1.91 \\
\hline & $20 \mathrm{~cm}$ & 5.59 & 1.52 & 1.42 & & $6 \mathrm{~cm}$ & 5.35 & 2.19 & 1.77 \\
\hline \multirow{5}{*}{$\begin{array}{l}\text { Concrete } \\
\text { block }\end{array}$} & $12 \mathrm{~cm}$ & 5.60 & 1.51 & 1.23 & & $7 \mathrm{~cm}$ & 5.04 & 2.63 & 1.99 \\
\hline & $24 \mathrm{~cm}$ & 5.88 & 1.55 & 1.38 & & $8 \mathrm{~cm}$ & 6.39 & 2.31 & 1.88 \\
\hline & $36 \mathrm{~cm}$ & 5.54 & 1.57 & 1.40 & & $9 \mathrm{~cm}$ & 4.23 & 1.98 & 1.62 \\
\hline & $48 \mathrm{~cm}$ & 5.26 & 1.61 & 1.66 & & $10 \mathrm{~cm}$ & 3.97 & 2.17 & \multirow[t]{2}{*}{1.86} \\
\hline & $60 \mathrm{~cm}$ & 5.25 & 1.90 & 1.94 & & & & & \\
\hline
\end{tabular}




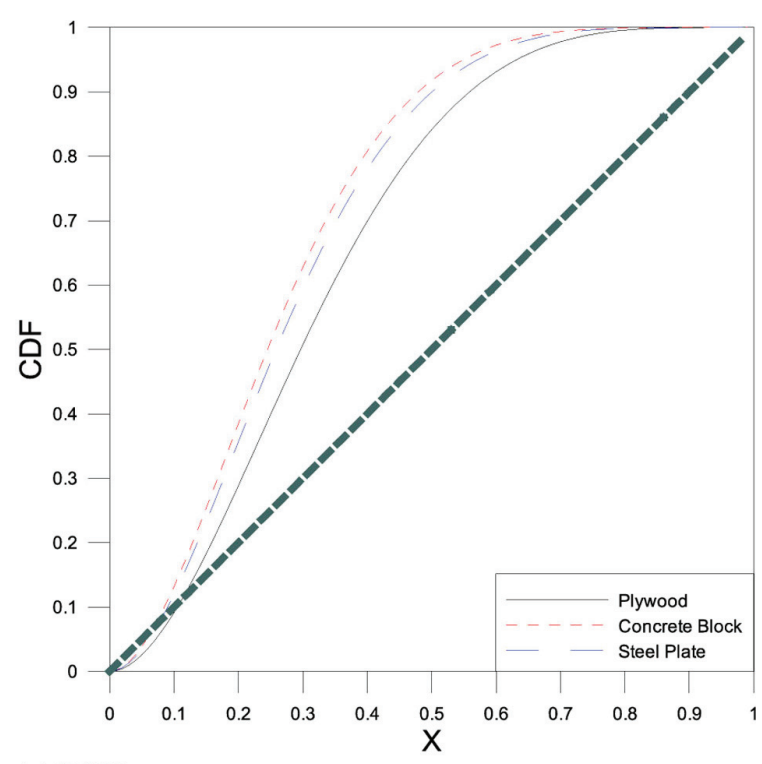

(a) RSSI

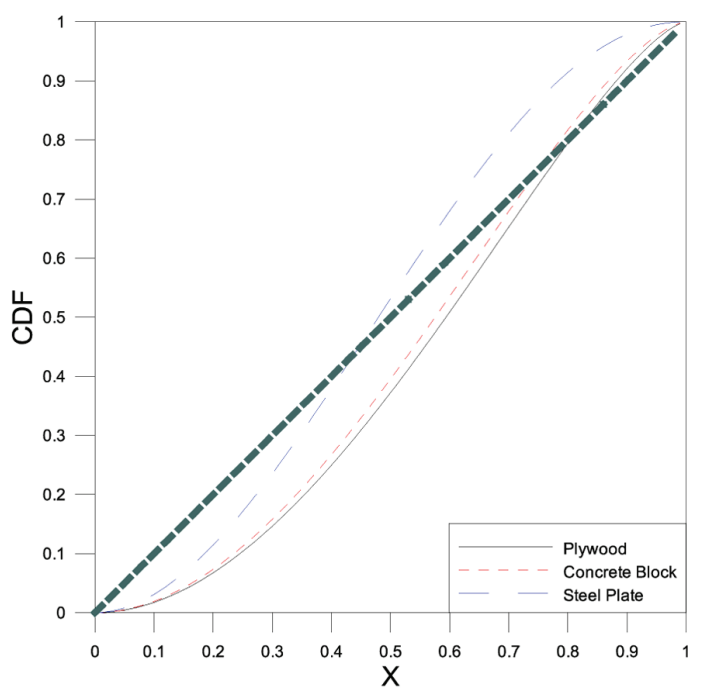

(b) LQI

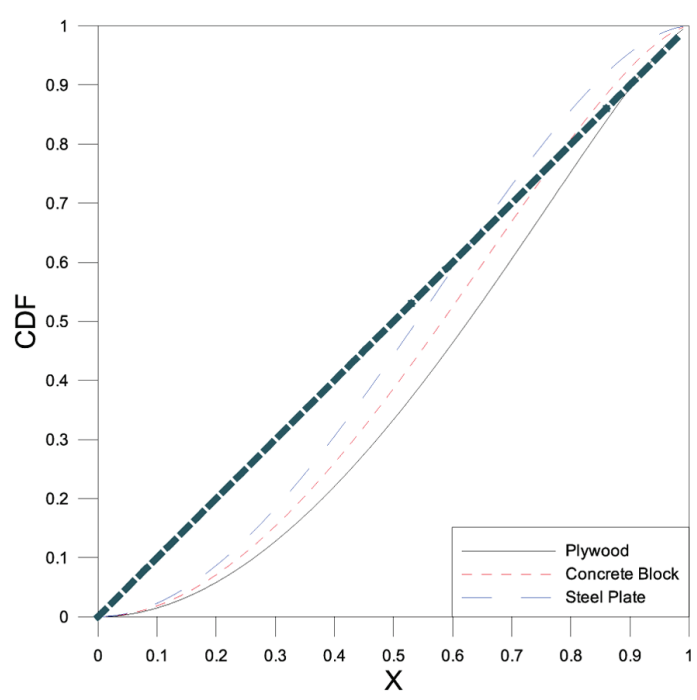

(c) PDR

Fig. 11. Cumulative distribution function in an obstructed environment e.g. moving to the left direction, such as a steel plate, the faster the measurement of the LQI or PDR decrease, indicating higher interference from the obstructions. If the CDF moves right, e.g. the more biased from a uniform distribution such as a concrete block or plywood, the higher probability that the LQI or PDR would be observed occurs toward the upper bound, remaining approximately $100 \%$ of the LQI or PDR, which indicates good performance reliability.

\section{Conclusions}

A typical construction site is a heterogeneous assortment of built structures, construction materials, and equipment by which wireless communication can be blocked or reflected. Obstructions in a construction site together with the various types of electromagnetic fields have adverse effects on the reliable performance of wireless communication. In addition, it is more complicated to evaluate the signal performance if the signal is interfered with by obstructions. Therefore, this paper examined a methodology to quantify the signal attenuation effect caused by major construction materials for potential WSN applications in civil infrastructure.

The results showed that the material type and thickness of the obstruction are the most critical components affecting the signal attenuation. The performance criteria, such as RSSI, LQI and PDR, decrease with increasing thickness of the materials, but the degree of signal attenuation is correlated with the physical characteristics of the materials. Generally, a wireless signal becomes poor in both signal strength and link quality as the penetrating thickness increases, and the packet reception rate decreases. In particular, with conducting materials, such as a steel plate, the degree of signal attenuation becomes more serious than with other dielectric materials. This phenomenon can be observed more quantifiably with a path loss exponent and attenuation index (AI) in that the obstructive environment of NLOS has a higher value of $n$ and AIs. The attenuation effects caused by different materials were also observed with a cumulative beta distribution.

It is concluded that the different characteristics of construction materials may affect the level of reliability performance in wireless communication. In particular, optimal placement of sensor nodes and network path, which are the critical requirements for successful WSN implementation in civil infrastructure, should be carefully investigated according to the materials type, penetration thickness, and T-R separation distance. Therefore, the results found in this research would provide a knowledge base in the area of sensor hardware design, field data collection, WSN application strategy, and network topology design.

\section{Acknowledgements}

This research was supported by the Yeungnam University research grants in 2013. 


\section{References}

Bae, S.-C.; Jang, W.-S.; Woo, S.; Shin, D. H. 2013. Prediction of WSN placement for bridge health monitoring based on material characteristics, Automation in Construction 35: 18-27. http://dx.doi.org/10.1016/j.autcon.2013.02.002

Bocca, M.; Eriksson, L. M.; Mahmood, A.; Jäntti, R.; Kullaa, J. 2011. A synchronized wireless sensor network for experimental modal analysis in structural health monitoring, Computer-Aided Civil and Infrastructure Engineering 26(7): 483-499.

http://dx.doi.org/10.1111/j.1467-8667.2011.00718.x

Boddu, R.; Balanagu, P.; Babu, N. S. 2012. Zigbee based mine safety monitoring system with GSM, International Journal of Computer and Communication Technology 3(5): 63-67.

Chae, M. J.; Yoo, H. S.; Cho, M. Y. 2012. Development of a wireless sensor network system for suspension bridge health monitoring, Automation in Construction 21: 237-252. http://dx.doi.org/10.1016/j.autcon.2011.06.008

Chang, D. T. T.; Tsai, Y. S.; Yang, K. C. 2013. Study of realtime slope stability monitoring system using wireless sensor network, Telkomnika 11(3): 1478-1488.

Halder, S. J.; Park, J. G.; Kim, W. 2011. Adaptive filtering for indoor localization using ZIGBEE RSSI and LQI measurement, in L. Garcia (Ed.). Adaptive Filtering Applications. InTech, 305-324.

Huang, L. C.; Chang, H. C.; Chen, C. C.; Kuo, C. C. 2011. A ZigBee-based monitoring and protection system for building electrical safety, Energy and Buildings 43(6): 1418-1426.

http://dx.doi.org/10.1016/j.enbuild.2011.02.001

Hwang, K. I.; Choi, B. J.; Kang, S. H. 2010. Enhanced selfconfiguration scheme for a robust ZigBee-based home automation, IEEE Transactions on Consumer Electronics 56(2): 583-590. http://dx.doi.org/10.1109/TCE.2010.5505974

Jadhavar, B. R.; Sontakke, T. R. 2012. 2.4 GHz propagation prediction models for indoor wireless communications within building, International Journal of Soft Computing and Engineering 2(3): 108-113.

Jo, B.-W.; Park, J.-H.; Yoon, K.-W. 2013. The experimental study on concrete permeability of wireless communication module embedded in reinforced concrete structures, International Journal of Distributed Sensor Networks 2013. http://dx.doi.org/10.1155/2013/520507

Kim, K. T.; Han, J. G. 2008. Design and implementation of a real-time slope monitoring system based on ubiquitous sensor network, in Proc. of the $25^{\text {th }}$ International Symposium on Automation and Robotics in Construction (ISARC2008), 26-29 June 2008, Vilnius, Lithuania, 330-336.

Kim, C.; Kim, H.; Ryu, J.; Kim, C. 2011. Ubiquitous sensor network for construction material monitoring, Journal of Construction Engineering and Management ASCE 137(2): 158-165. http://dx.doi.org/10.1061/(ASCE)CO.1943-7862.0000257

Kim, J. R.; Yoo, H. S.; Kwon, S. W.; Cho, M. Y. 2008. Integrated tunnel monitoring system using wireless automated data collection technology, in Proc. of the $25^{\text {th }}$ International Symposium on Automation and Robotics in Construction (ISARC2008), 26-29 June 2008, Vilnius, Lithuania, 337-342.

Nadimi, E. S.; Søgaard, H. T.; Bak, T.; Oudshoorn, F. W. 2008. ZigBee-based wireless sensor networks for monitoring animal presence and pasture time in a strip of new grass, Computers and Electronics in Agriculture 61(2): 79-87.

http://dx.doi.org/10.1016/j.compag.2007.09.010

Naticchia, B.; Vaccarini, M.; Carborari, A. 2013. A monitoring system for real-time interference control on large construction sites, Automation in Construction 29: 148-160. http://dx.doi.org/10.1016/j.autcon.2012.09.016

Lee, H. J.; Lee, S. H.; Ha, K. S.; Jang, H. C.; Chung, W. Y.; Kim, J. Y.; Chang, Y. S.; Yoo, D. H. 2009. Ubiquitous healthcare service using Zigbee and mobile phone for elderly patients, International Journal of Medical Informatics 78(3): 193-198.

http://dx.doi.org/10.1016/j.ijmedinf.2008.07.005

Liu, C. H.; Teng, P. C. 2010. The study for bridge monitoring system of attacks analysis, in Proc. of the International Conference on Advances in Energy Engineering (ICAEE2010), 19-20 June 2010, Beijing, China, 142-145.

Panitz, M.; Christopoulos, C.; Sewell, P.; Hope, D.; Dawson, J.; Marvin, A. 2008. Modeling wireless communication in highly-multipath low-loss environments, in Proc. of the International Symposium on Electromagnetic Compatibility - EMC Europe, 8-12 September 2008, Hamburg, Germany, 709-714.

Raj, M.; Varghese, K. 2012. Positioning of human resources in a construction environment using ZigBee, Gerontechnology 11(2): 418-427. http://dx.doi.org/10.4017/gt.2012.11.02.290.00

Rasin, Z.; Hamzah, H.; Aras, M. S. M. 2009. Application and evaluation of high power Zigbee based wireless sensor network in water irrigation control monitoring system, in Proc. of IEEE Symposium on Industrial Electronics and Applications (ISIEA2009), 4-6 October 2009, Kuala Lumpur, Malaysia, 548-551.

Seidel, S. Y.; Rappaport, T. 1992. 914 MHz path loss prediction models for indoor wireless communications in multifloored buildings, IEEE Transactions on Antennas and Propagation 40(2): 207-217.

http://dx.doi.org/10.1109/8.127405

Sung, T. W.; Yang, C. S. 2010. An adoptive joining mechanism for improving the connection ratio of ZigBee wireless sensor networks, International Journal of Communication Systems 23(2): 231-251. http://dx.doi.org/10.1002/dac.1067

Sung, T. W.; Wu, T. T.; Yang, C. S.; Huang Y. M. 2010. Reliability data broadcast for Zigbee wireless sensor networks, International Journal on Smart Sensing and Intelligent Systems 3(3): 504-520.

Xiao, H.; Gong, Y.; Ogai, H.; Zhang, Z. 2011. A data collection system in wireless network integrated WSN and ZigBee for bridge health diagnosis, in Proc. of in International Conference on Instrumentation, Control, Information Technology and System Integration (SICE2011), 13-18 September 2011, Tokyo, Japan, 2024-2028.

Yang, G.; Liang, H.; Wu, C.; Cao, X. 2012. Construction hoist security application for tall building construction in wireless networks, Automation in Construction 27: $147-154$. http://dx.doi.org/10.1016/j.autcon.2012.04.010

Zhang, Z. Y.; Wei, Z. 2012. Research on positioning and tracking system of construction workers based on ZigBee, in Proc. of the $3^{\text {rd }}$ International Conference on Computer and Electrical Engineering (ICCEE2010), 16-18 November 2010, Chengdu, China, 474-478. 
Won-Suk JANG. Dr, Associate Professor in the Department of Civil Engineering, College of Engineering at Yeungnam University, South Korea. Member of Korean Society of Civil Engineers (KSCE), Korea Institute of Construction Engineering and Management (KICEM), Korean Society of Ubiquitous Monitoring (KSUM), and Korean Institute of Building Information Modeling (KIBIM). His research interests include IT-based Civil and Infrastructure Engineering and Management, such as applications of wireless sensor network, web-based project management systems, and construction assets tracking, and building information modelling.

Du Yon KIM. Dr, Assistant Professor in the School of Construction Engineering, College of Engineering at Kyungil University, South Korea. Member of Korean Society of Civil Engineers (KSCE) and Korea Institute of Construction Engineering and Management (KICEM). His research interests include risk management for international construction projects, financial decision analysis, infrastructure asset management, and lifecycle cost management.

Mirosław J. SKIBNIEWSKI. Dr, Professor of Construction Engineering and Project Management at the University of Maryland in College Park, USA. An author or co-author of over 250 publications, he is a Member of American Society of Civil Engineers (ASCE); a Founding Member, Co-director and past President of International Association for Automation and Robotics in Construction (IAARC); and an Affiliate of International Council for Building Research Studies and Documentation (CIB). His current research interests include construction automation and robotics, information technology in construction, e-commerce technology applications in construction, and green intelligent buildings. Among his awards, is an Honorary Doctorate from Vilnius Gediminas Technical University presented in 2009. 